\title{
Focal Adhesion Targeting: The Critical Determinant of FAK Regulation and Substrate Phosphorylation
}

\author{
Yu Shen* and Michael D. Schaller*t
}

\author{
*Department of Cell Biology and Anatomy and 'Lineberger Comprehensive Cancer Center, \\ University of North Carolina at Chapel Hill, Chapel Hill, North Carolina 27599
}

Submitted January 27, 1999; Accepted May 17, 1999

Monitoring Editor: Joan Brugge

\begin{abstract}
The focal adhesion kinase (FAK) is discretely localized to focal adhesions via its C-terminal focal adhesion-targeting (FAT) sequence. FAK is regulated by integrin-dependent cell adhesion and can regulate tyrosine phosphorylation of downstream substrates, like paxillin. By the use of a mutational strategy, the regions of FAK that are required for cell adhesion-dependent regulation and for inducing tyrosine phosphorylation of paxillin were determined. The results show that the FAT sequence was the single region of FAK that was required for each function. Furthermore, the FAT sequence of FAK was replaced with a focal adhesion-targeting sequence from vinculin, and the resulting chimera exhibited cell adhesion-dependent tyrosine phosphorylation and could induce paxillin phosphorylation like wild-type FAK. These results suggest that subcellular localization is the major determinant of FAK function.
\end{abstract}

\section{INTRODUCTION}

The integrins are cell surface receptors that bind to extracellular matrix proteins or proteins on the surface of other cells (Hynes, 1992). Integrin-dependent adhesion to the extracellular matrix is important for a variety of important biological events including morphogenesis (Faraldo et al., 1998), angiogenesis (Brooks et al., 1994; Friedlander et al., 1995), cell cycle progression (Assoian and Zhu, 1997), cell migration (Yamada et al., 1992; Jones et al., 1995), and regulation of apoptosis (Meredith and Schwartz, 1993; Frisch and Francis, 1994). Engagement of the integrins with the extracellular matrix triggers a complex signaling cascade that presumably functions in controlling some of these biological events. Integrin-dependent adhesion triggers changes in intracellular pH (Schwartz et al., 1989, 1990) and levels of cytoplasmic calcium (Schwartz, 1993), activation of phosphatidylinositol 3'-kinase (King et al., 1997; Shaw et al., 1997), and stimulation of both serine and threonine kinases and protein tyrosine kinases (PTKs) ${ }^{1}$ (Burridge et al., 1992; Guan and Shalloway, 1992; Hanks et al., 1992; Lipfert et al., 1992). Results from pharmacological studies suggest that PTKs are required for some integrin-dependent biological functions such as organization of the cytoskeleton and cell migration (ChrzanowskaWodnicka and Burridge, 1994; Romer et al., 1994). A number of PTKs have been implicated in integrin-regulated signaling. The

‡ Corresponding author. E-mail address: crispy4@med.unc.edu. Abbreviations used: CE, chicken embryo; FAK, focal adhesion kinase; FAT, focal adhesion targeting; PCR, polymerase chain reaction; PTK, protein tyrosine kinase; PTP, protein tyrosine phosphatase; $\mathrm{SH}, \mathrm{Src}$ homology. focal adhesion kinase (FAK) was the first PTK identified as an integrin-regulated PTK. FAK colocalizes with integrins in focal adhesions, and its phosphotyrosine content and enzymatic activity are elevated upon integrin-dependent cell adhesion (Burridge et al., 1992; Guan and Shalloway, 1992; Hanks et al., 1992; Lipfert et al., 1992; Schaller et al., 1992). An FAK-related PTK, known as CAK $\beta$, Pyk2, CADTK, RAFTK, and FAK2, has also been reported to be regulated by integrins (Li et al., 1996). However, under other conditions FAK and CAK $\beta$ are clearly regulated differently (Brinson et al., 1998; Zheng et al., 1998). In platelets, Syk is activated after stimulation with agonists, e.g., thrombin, partially via integrin-dependent and partially via integrin-independent mechanisms (Clark et al., 1994). Syk is also activated during adhesion of monocytes (Lin et al., 1995). Integrin-dependent cell adhesion also triggers a transient relocalization of $\mathrm{Abl}$ from the nucleus to focal adhesions, accompanied by a transient elevation in catalytic activity (Lewis et al., 1996). These observations have implicated multiple PTKs in the transduction of cytoplasmic signals after cell adhesion.

Of these PTKs, FAK may be particularly important because it has been implicated in controlling several integrindependent biological processes. By the use of a dominantnegative approach, FAK was shown to be necessary for the migration of endothelial cells (Gilmore and Romer, 1996). This result is consistent with results using fibroblasts derived from $f a k^{-/-}$embryos, which also exhibit a migration defect (Ilic et al., 1995). Conversely, overexpression of FAK can enhance cell motility (Cary et al., 1996). Two lines of evidence also suggest that FAK may function in transmitting an integrin-dependent cell survival signal. First, microinjection of FAK antibodies induces apoptosis in fibroblasts (Hungerford et al., 1996). Second, overexpression of a chi- 
meric FAK molecule that is constitutively active prevents MDCK cells from undergoing apoptosis when detached from the extracellular matrix (Frisch et al., 1996). Results using a dominant-negative FAK construct also suggest that FAK functions in controlling the rate of cell spreading after adhesion to fibronectin (Richardson and Parsons, 1996).

FAK is a structurally unique protein tyrosine kinase with large $\mathrm{N}$ - and C-terminal domains flanking the central catalytic domain (Hanks et al., 1992; Schaller et al., 1992). The N-terminal domain of FAK can bind a synthetic peptide mimicking the cytoplasmic domain of the $\beta_{1}$ integrin subunit in vitro (Schaller et al., 1992). The C-terminal noncatalytic domain, specifically the C-terminal 150 residues, functions as the focal adhesion-targeting (FAT) sequence of FAK and is responsible for localizing FAK to the correct region of the cell (Hildebrand et al., 1993). In addition, the C-terminal domain serves as a docking site for a number of cytoskeletal and signaling molecules, several of which become tyrosine phosphorylated after integrin-dependent adhesion. These FAK-binding partners include talin, paxillin, GRAF (GTPase regulator associated with FAK), and p130 cas (Turner and Miller, 1994; Chen et al., 1995; Hildebrand et al., 1995, 1996; Polte and Hanks, 1995; Harte et al., 1996). Tyrosine phosphorylation of FAK is critical for its function. Phosphorylation of catalytic domain tyrosine residues enhances enzymatic activity (Calalb et al., 1995). Phosphorylation of other tyrosine residues creates binding sites for Src homology 2 (SH2) domain-containing signaling molecules like Src and Grb2 (Schaller et al., 1994; Schlaepfer et al., 1994). Based on these observations, the C-terminal domain of FAK functions in subcellular localization and directing the transmission of downstream signaling, i.e. by binding and recruiting substrates. By default, we anticipated that the N-terminal domain of FAK likely served a regulatory role and might link FAK to integrin signaling.

In this study, we begin to explore the mechanism of FAK activation after the engagement of integrins with extracellular matrix. A series of FAK mutants was analyzed for their response to integrin-dependent cell adhesion. Our results indicate that the N-terminal noncatalytic domain was dispensable for adhesion-dependent tyrosine phosphorylation of FAK. The focal adhesion-targeting sequence of FAK was the only domain that was crucial for tyrosine phosphorylation of FAK in response to plating cells on fibronectin. A chimeric protein containing the catalytic domain of FAK and the N-terminal focal adhesion-targeting domain of vinculin localized to focal adhesions and exhibited cell adhesiondependent tyrosine phosphorylation. Furthermore, the chimera could induce tyrosine phosphorylation of paxillin, a potential downstream effector of the FAK-signaling pathway. These results suggest that the focal adhesion localization of FAK confers its adhesion-dependent regulation and its ability to transmit downstream signals.

\section{MATERIALS AND METHODS}

\section{Cells and Virus}

Embryonated chick eggs, from group-specific negative White Leghorn chickens, were purchased from Spafas (Norwich, CT) and used to prepare chicken embryo (CE) cells as described (Reynolds et al., 1989). The cells were maintained at $37^{\circ} \mathrm{C}$, in an atmosphere of $5 \%$ $\mathrm{CO}_{2}$ in DMEM medium supplemented with $4 \%$ fetal bovine serum and $1 \%$ chicken serum. Replication-competent avian retroviral vectors (RCAS A and RCAS B) were used to express exogenous proteins in CE cells as described (Hildebrand et al., 1993; Schaller et al., 1993).

\section{Molecular Biology}

FAK mutants dl 853-963, dl 965-1012, dl 51-377, dl 721-857, FAK $^{454 \mathrm{R}}$, FAK $^{564 \mathrm{~A}}$, and FAK ${ }^{397 \mathrm{~F}}$ have been described (Hildebrand $e t$ al., 1993; Schaller et al., 1994). To generate dl 1-361, we amplified nucleotides 1124-2258 (encoding amino acids 361-740) of FAK by polymerase chain reaction (PCR). The $5^{\prime}$ PCR primer created a BamHI site to facilitate cloning. The amplified sequence was ligated in-frame with an engineered initiation codon and a KT3 epitope tag upstream and FAK codons 742-1052 downstream in the pBluescript vector. This plasmid, pBluescript 1124 FAK, was further used to generate the FAK/vinculin chimera. The sequence encoding amino acids $1-400$ of vinculin was amplified by PCR. This DNA fragment was inserted between the NdeI site (base pair 2250) of FAK and the SalI site in the multiple cloning site of pBluescript 1124 FAK. The vinculin sequences were engineered in-frame with FAK sequences. The nucleotide sequence of all amplified DNA fragments was determined using Sequenase (United States Biochemical, Cleveland, $\mathrm{OH})$. No mutations attributable to PCR amplification were found. The 1124 FAK and FAK/vinculin chimera sequences were then subcloned into the replication-competent avian retroviral expression vector RCAS A.

\section{Induction of Tyrosine Phosphorylation In Vivo}

Plastic dishes were coated with fibronectin (Sigma, St. Louis, MO) at $6 \mu \mathrm{g} / \mathrm{cm}^{2}$ or with poly-L-lysine (Sigma) at $0.05 \mathrm{mg} / \mathrm{cm}^{2}$. Subconfluent CE cells were trypsinized, washed in phosphate-buffered saline containing $0.5 \mathrm{mg} / \mathrm{ml}$ soybean trypsin inhibitor (Sigma), resuspended in serum-free culture medium, and kept in suspension at $37^{\circ} \mathrm{C}$ for $45-60 \mathrm{~min}$. The cells were then plated onto fibronectin- or poly-L-lysine-coated dishes and incubated at $37^{\circ} \mathrm{C}$. Unless indicated otherwise, the cells were lysed after a $30-45 \mathrm{~min}$ incubation at $37^{\circ} \mathrm{C}$. In some experiments cells were incubated in culture media containing $50 \mu \mathrm{M}$ vanadate overnight.

\section{Protein Analysis}

Monolayers of cells were lysed in ice-cold modified radioimmunoprecipitation assay buffer (50 mM Tris- $\mathrm{HCl}, \mathrm{pH} 7.3,150 \mathrm{mM} \mathrm{NaCl}$, $1 \%$ Nonidet P- $40,0.5 \%$ deoxycholate, $0.5 \%$ aprotinin, $1 \mathrm{mM}$ PMSF, $1.5 \mathrm{mM}$ orthovanadate). The protein concentrations of the lysates were determined using the bicinchoninic acid assay (Pierce Chemical, Rockford, IL). Immunoprecipitation and Western blotting were performed as described (Schaller et al., 1992, 1994). BC4 antiserum was used to recognize untagged FAK variants, and monoclonal antibody KT3 was used to recognize epitope-tagged variants (BC4 was prepared identically to the $\mathrm{BC} 3$ antiserum) (MacArthur and Walter, 1984; Schaller et al., 1992). BC2, a polyclonal antiserum raised against the kinase domain of FAK, was used for the analysis of the FAK/vinculin chimera (Richardson and Parson, 1996). Commercially available monoclonal antibodies were used for the detection of paxillin and phosphotyrosine (Transduction Laboratories, Lexington, KY). For in vitro kinase assays, immune complexes were washed three times in kinase reaction buffer $[10 \mathrm{mM}$ piperazine$N, N^{\prime}$-bis(2-ethanesulfonic acid), $\left.\mathrm{pH} 7.2,3 \mathrm{mM} \mathrm{MnCl}_{2}\right]$ and then incubated in kinase reaction buffer containing $10 \mu \mathrm{Ci}\left[\gamma^{-32} \mathrm{P}\right] \mathrm{ATP}$ (Dupont New England Nuclear, Wilmington, DE) at $37^{\circ} \mathrm{C}$ for 30 min. The immune complexes were then analyzed by SDS-PAGE and autoradiography.

\section{Immunofluorescence}

Immunofluorescence experiments were performed as described previously (Schaller et al., 1992, 1993). Cells at 60-80\% confluence 
were fixed in $3.7 \%$ formaldehyde for $10 \mathrm{~min}$ and permeabilized in $0.5 \%$ Triton X-100 for 5 min. The FAK/vinculin chimera and wildtype FAK were detected using $\mathrm{BC} 2$. For these experiments the immunoglobulin fraction of the whole serum was purified by affinity chromatography on a protein A sepharose column. The primary antibody was detected by a fluorescein-conjugated anti-rabbit secondary antibody (Jackson ImmunoResearch Laboratories, West Grove, PA). Cells were costained with a paxillin monoclonal antibody (Transduction Laboratories) and a rhodamine-conjugated anti-mouse secondary antibody (Jackson ImmunoResearch Laboratories).

\section{RESULTS}

\section{Exogenously Expressed FAK and Endogenous FAK Are Similarly Regulated by Cell Adhesion}

The phosphotyrosine content of FAK is regulated in a cell adhesion-dependent manner. To determine which regions of FAK are required for cell adhesion-dependent tyrosine phosphorylation, a series of FAK mutants were analyzed. Before analyzing the mutants, it was necessary to establish that exogenously expressed FAK was regulated by cell adhesion. Wild-type FAK constructs, both untagged and epitope tagged, were expressed in CE cells using an avian retroviral expression vector, RCAS A. Cells were detached by trypsinization and incubated in suspension in serum-free media to allow dephosphorylation of FAK. Cells were then plated onto poly-L-lysine- or fibronectin-coated plates. The tyrosine phosphorylation of FAK was determined by immunoprecipitating FAK and Western blotting with an antibody against phosphotyrosine. Both endogenous and exogenously expressed FAK were phosphorylated on tyrosine in cultured CE cells (Figure 1). Tyrosine phosphorylation on FAK was diminished when cells were trypsinized and held in suspension. The phosphotyrosine content of endogenous FAK and both exogenously expressed untagged FAK and epitope-tagged FAK increased after cell adhesion to fibronectin (Figure 1). The phosphotyrosine content of each remained low when cells adhered to poly-L-lysine. Equal amounts of FAK were present in immunoprecipitates from lysates of cells in culture, cells plated on poly-L-lysine, and cells plated on fibronectin (Figure 1). This result indicates that the exogenously expressed FAK and endogenous FAK are similarly regulated by cell adhesion.

\section{Focal Adhesion Targeting Is Critical for Cell Adhesion-dependent Regulation}

The N-terminal domain of FAK binds synthetic peptides mimicking the cytoplasmic domain of integrin $\beta$ subunits. To determine the importance of this interaction in the regulation of FAK phosphorylation, two mutants with large N-terminal deletions were analyzed. Both dl 1-361 and dl 51-377 were highly phosphorylated on tyrosine in cells growing in culture. They exhibited reduced tyrosine phosphorylation in suspension or after plating onto poly-L-lysine-coated plates, and each became tyrosine phosphorylated after cell adhesion to fibronectin (Figure 2A, top). Equivalent amounts of protein were recovered in each immune complex (Figure 2A, bottom). The response of each of these mutants was comparable with that of wild-type FAK. Thus the entire N-terminus is dispensable for cell adhesiondependent regulation.
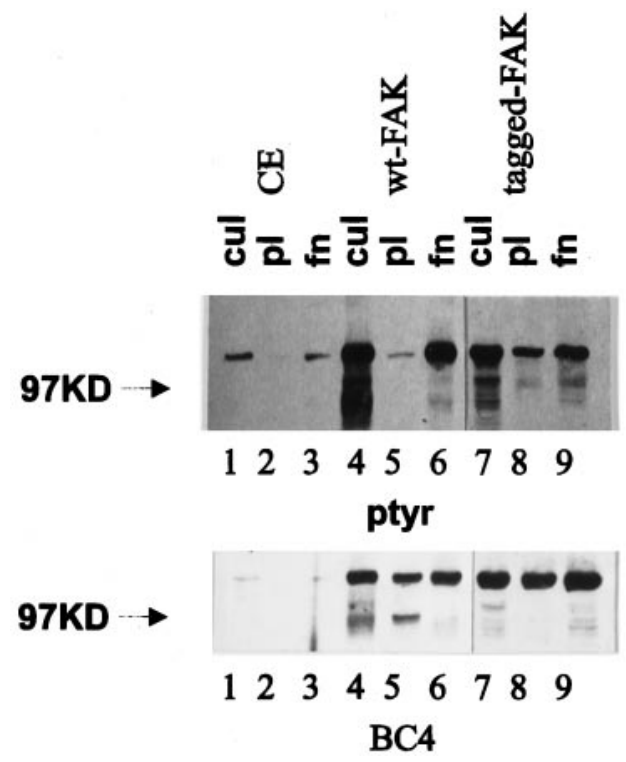

Figure 1. Cell adhesion-dependent regulation of exogenously expressed FAK. CE cells transfected with empty RCAS (lanes 1-3) or RCAS containing wild-type (wt) FAK (lanes 4-6) or epitope-tagged FAK (lanes 7-9) were trypsinized, kept in suspension for 45-60 min, and plated on poly-L-lysine- or fibronectin-coated plates for 30-45 min. Subconfluent cells growing in culture (cul; lanes 1, 4, and 7) or cells plated on poly-L-lysine-coated plates ( $\mathrm{pl}$; lanes 2, 5, and 8) or fibronectin-coated plates (fn; lanes 3, 6, and 9) were lysed, and FAK was immunoprecipitated with BC4. Samples were separated by SDS-PAGE, transferred to nitrocellulose, and blotted with an antiphosphotyrosine antibody (ptyr; top) or BC4 (bottom). The arrowheads indicate the position of the $97-\mathrm{kDa}$ molecular weight marker.

A series of C-terminal deletion mutants was also analyzed for their abilities to respond to cell adhesion. dl 721-857, a deletion mutant lacking the sequences between the catalytic domain and the focal adhesion-targeting sequence, exhibited cell adhesion-dependent tyrosine phosphorylation similar to that of wild-type FAK (Figure 2B). Thus these sequences are not required for cell adhesion-dependent tyrosine phosphorylation. Mutants dl 853-963 and dl 9651012 have defects within the focal adhesion-targeting sequence and consequently are diffusely localized throughout the cell rather than discretely localized to focal adhesions (Hildebrand et al., 1993). dl 853-963 was tyrosine phosphorylated in subconfluent CE cells growing in culture. Its phosphotyrosine content diminished upon trypsinization and incubation in suspension. However, plating cells onto fibronectin did not induce its tyrosine phosphorylation (Figure 3, lanes 4-6). dl 965-1012 was highly phosphorylated on tyrosine in CE cells growing in culture. Trypsinization and incubation in suspension for $45 \mathrm{~min}$ did not cause the dephosphorylation of this mutant, and plating cells on fibronectin did not further increase its tyrosine phosphorylation (Figure 3, lanes 7-9). To examine the dephosphorylation of dl 853-963 and dl 965-1012 more carefully, we detached cells expressing each of the constructs and kept the cells in suspension for various times in serum-free media. Tyrosine phosphorylation of the mutants was examined by immunoprecipitation and Western blotting. dl 853-963 became max- 


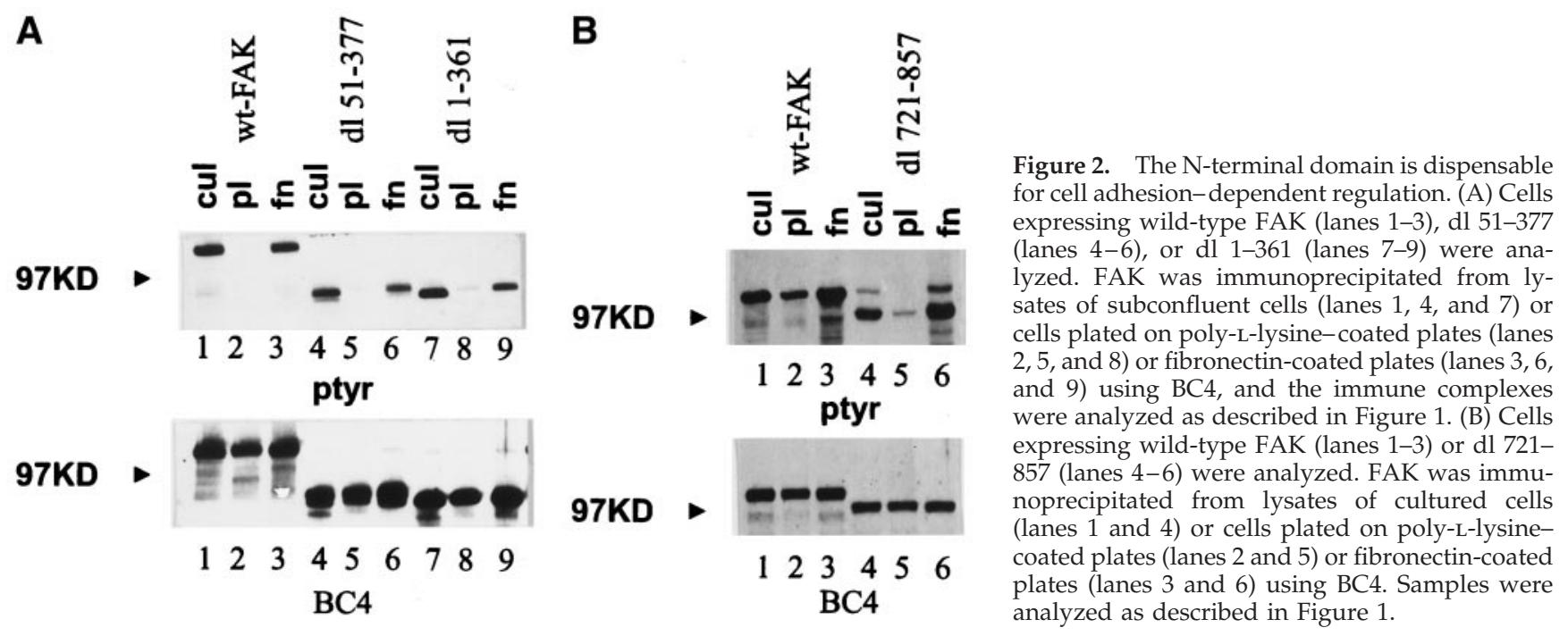

imally dephosphorylated after incubation in suspension for $1 \mathrm{~h}$. In contrast, dl 965-1012 still contained relatively high levels of phosphotyrosine even after incubation for $3 \mathrm{~h}$ at $37^{\circ} \mathrm{C}$ in suspension (Figure 4). This mutant is apparently deficient for removal of phosphotyrosine when cells are detached from their extracellular matrix.

The mutants dl 853-963 and dl 965-1012 were further characterized in an effort to elucidate how their phosphoty-

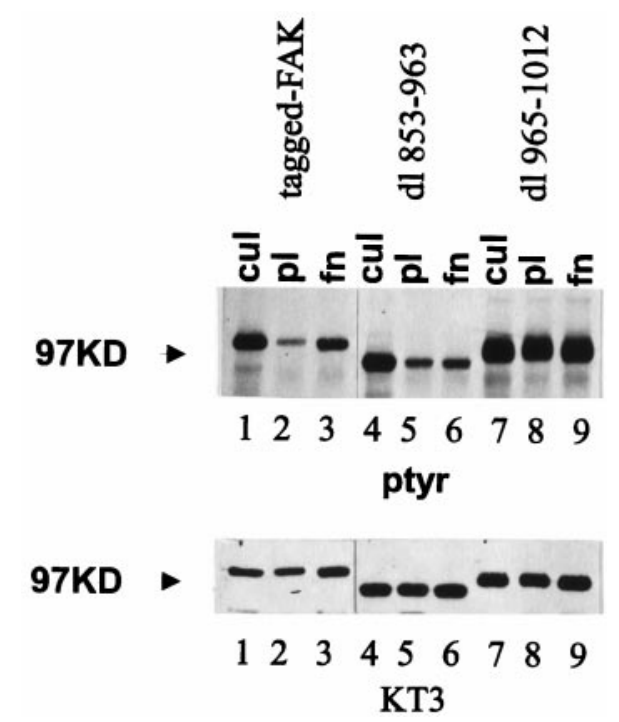

Figure 3. The FAT sequence is required for integrin-dependent regulation. Cells expressing epitope-tagged wild-type FAK (lanes 1-3), tagged dl 853-963 (lanes 4-6), or tagged dl 965-1012 (lanes 7-9) were analyzed. Exogenously expressed, tagged FAK was immunoprecipitated from lysates of cultured cells (lanes 1, 4, and 7) or cells plated on poly-L-lysine-coated plates (lanes 2,5 , and 8) or fibronectin-coated plates (lanes 3, 6, and 9) using the KT3 antibody. The immune complexes were analyzed by Western blotting for phosphotyrosine (top) and for the amount of protein present using KT3 (bottom). The position of the 97-kDa molecular weight marker is indicated by the arrowheads. rosine content was regulated. To determine whether the mutants were indeed regulated by cell adhesion, but with dramatically delayed kinetics, a time course experiment was performed. CE cells expressing dl 853-963 were plated onto fibronectin- or poly-L-lysine-coated dishes and lysed after incubation at $37^{\circ} \mathrm{C}$ for various times. The mutant protein was immunoprecipitated using BC4, and its phosphotyrosine content was examined by Western blotting. The level of tyrosine phosphorylation dramatically decreased in cells in suspension (Figure 5A, top, lane 2). The phosphotyrosine content of dl 853-963 remained low in cells plated on fibronectin for up to $3 \mathrm{~h}$. Similar levels of tyrosine phosphorylation were seen in samples from cells plated on fibronectin and poly-L-lysine for $3 \mathrm{~h}$ (Figure 5A, top, lanes 5 and 6). Equivalent amounts of protein were recovered from each

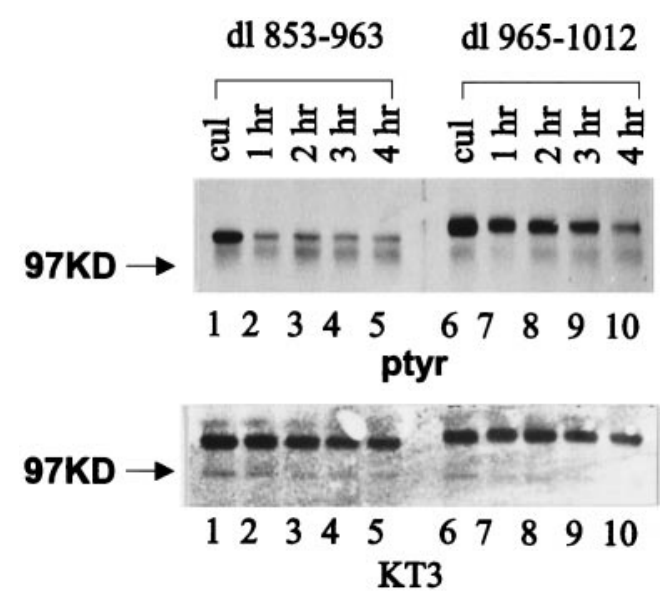

Figure 4. Time-dependent dephosphorylation of dl 853-965 and dl 965-1012 in cells in suspension. Cells expressing dl 853-965 (lanes 1-5) or dl 965-1012 (lanes 6-10) were trypsinized and kept in suspension in serum-free medium for various times. The proteins were immunoprecipitated from lysates of cultured cells (lanes 1 and 6) or cells kept in suspension for 1-4 h (lanes 2-5 and 7-10) with KT3. Samples were analyzed as described in Figure 3. 
A

B
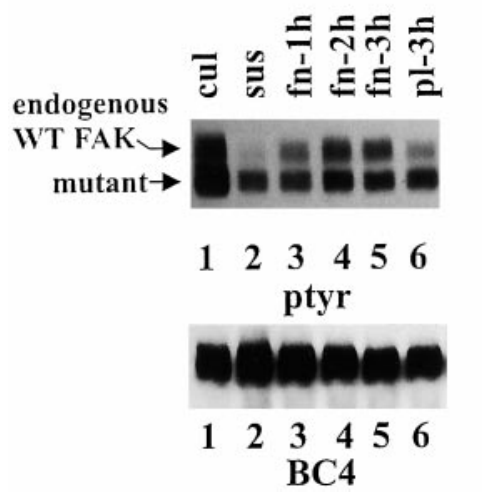

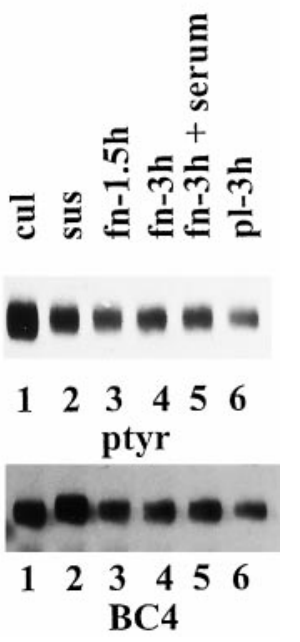

Figure 5. Kinetic analysis of $\mathrm{dl}$ 853-963 and $\mathrm{dl}$ 965-1012 phosphorylation upon cell adhesion. (A) Cells expressing dl 853-963 were held in suspension for $45 \mathrm{~min}$ in serum-free medium and then plated onto fibronectin- or poly-L-lysine-coated dishes. Cells in culture (lane 1), cells in suspension (lane 2), and cells plated onto fibronectin for $1 \mathrm{~h}$ (lane 3), $2 \mathrm{~h}$ (lane 4 ), or $3 \mathrm{~h}$ (lane 5) or cells plated onto poly-L-lysine for $3 \mathrm{~h}$ (lane 6) were lysed. FAK was immunoprecipitated using $\mathrm{BC} 4$, and the immune complexes were analyzed by Western blotting for phosphotyrosine (top). Endogenous wildtype FAK and mutant FAK are indicated by arrowheads. The blot was stripped and reprobed with BC4 (bottom). (B) Cells expressing dl 965-1012 were held in suspension for $4 \mathrm{~h}$ in serum-free medium and then plated onto fibronectin- or poly-L-lysine-coated dishes. Cells in culture (lane 1), cells in suspension (lane 2), and cells plated onto fibronectin for $1.5 \mathrm{~h}$ (lane 3 ) or $3 \mathrm{~h}$ (lane 4 ) or cells plated onto poly-L-lysine for $3 \mathrm{~h}$ (lane 6) were lysed. To test for the effects of serum, cells were adhered to fibronectin in serum-free medium for $1.5 \mathrm{~h}$ and then stimulated with culture medium for $1.5 \mathrm{~h}$ before lysis (lane 5). FAK was immunoprecipitated using BC4, and the immune complexes were analyzed by Western blotting for phosphotyrosine (top). The blot was stripped and reprobed with BC4 (bottom).

lysate (Figure 5A, bottom). Because BC4 was used in this analysis, endogenous wild-type FAK was also immunoprecipitated. In contrast to that of dl 853-963, the level of tyrosine phosphorylation of endogenous wild-type FAK was clearly regulated by adhesion to fibronectin (Figure 5A, top). Although tyrosine phosphorylation of dl 965-1012 did not appear to increase upon cell adhesion to fibronectin (Figure 3), the high level of phosphorylation in the negative control made interpretation difficult. To alleviate this difficulty, we held cells expressing dl 965-1012 in suspension for $4 \mathrm{~h}$ in serum-free medium at $37^{\circ} \mathrm{C}$ before plating these cells on fibronectin or poly-L-lysine. Cells were lysed at various times, and the mutant protein was analyzed by immunoprecipitation and Western blotting. The phosphotyrosine content of dl 965-1012 was reduced in cells held in suspension, and cell adhesion to fibronectin did not induce an increase in tyrosine phosphorylation of the protein (Figure 5B, top). Thus neither dl 853-963 nor dl 965-1012 became tyrosine phosphorylated even upon prolonged incubation on fibronectin.

Because tyrosine phosphorylation of FAK can be regulated by a number of stimuli found in serum, including

growth factors and lysophosphatidic acid (Barry and Critchley, 1994; Rankin and Rozengurt, 1994; Seufferlein and Rozengurt, 1994; Abedi et al., 1995), it was possible that tyrosine phosphorylation of dl 853-963 and dl 965-1012 was regulated by serum. This possibility was addressed in two ways. First, CE cells expressing dl 853-963 or dl 965-1012 were serum starved (Catling et al., 1993), and tyrosine phosphorylation was examined by immunoprecipitation and Western blotting. Even after starvation for $48 \mathrm{~h}$, the phosphotyrosine content of these two mutants did not decline (Gabarra and Schaller, unpublished observations). Second, cells expressing dl 853-963 or dl 965-1012 were plated on fibronectin in medium containing serum (either $20 \%$ fetal calf serum or normal culture medium containing $4 \%$ fetal calf serum and $1 \%$ chick serum). Alternatively cells were allowed to adhere in serum-free medium and then were stimulated with serum-containing medium. Under each of these conditions, the presence of serum had no effect on the phosphotyrosine content of dl 853-963 or dl 965-1012 (Figure 5B, top, lanes 4 and 5) (Gabarra and Schaller, unpublished observations). Therefore tyrosine phosphorylation of these mutants is not regulated by serum.

\section{The N-Terminal Domain and Kinase Activity of FAK Are Not Required for the FAK-dependent Tyrosine Phosphorylation of Paxillin}

Paxillin is an FAK-binding protein that localizes to focal adhesions and undergoes tyrosine phosphorylation in an FAK-dependent manner. Treatment of FAK-overexpressing CE cells, but not control CE cells, with sodium vanadate results in a dramatic increase in the phosphotyrosine content of paxillin (Figure 6A, lanes 1-4) (Schaller and Parsons, 1995). It has been shown that dl 853-963, dl 965-1012, and FAK $^{397 F}$ are deficient in inducing tyrosine phosphorylation of paxillin in this assay (Schaller and Parsons, 1995). To determine whether there are other sequences of FAK that are required for induction of paxillin tyrosine phosphorylation, a series of mutants was tested for their ability to induce paxillin phosphorylation upon vanadate treatment. Tyrosine phosphorylation of paxillin was examined by immunoprecipitation and Western blotting. dl 1-361 and dl 51-377 induced tyrosine phosphorylation of paxillin as effectively as did wild-type FAK. Thus the N-terminal domain of FAK is not required for inducing tyrosine phosphorylation of paxillin (Figure 6A, lanes 5-8). Similarly, dl 721-857 also induced tyrosine phosphorylation of paxillin (Figure 6B, lanes 5 and 6), indicating that the sequences between the catalytic domain and the focal adhesion-targeting sequence are dispensable for downstream signaling by FAK. Interestingly, the two catalytically inactive variants $F^{4} K^{454 R}$ and FAK ${ }^{564 A}$ retained the ability to induce tyrosine phosphorylation of paxillin, although they did so less well than did wild-type FAK (Figure 6B, lanes 7-10). Previous results have implicated the focal adhesion-targeting sequence and tyrosine 397 as essential features for inducing tyrosine phosphorylation of paxillin. Further analysis has not revealed any additional sequences that are necessary to induce phosphorylation of paxillin. These results demonstrate the fundamental importance of the focal adhesion-targeting sequence and subcellular localization both in the regulation of FAK in response to cell adhesion and in the transmission of a signal to downstream effector proteins, e.g., paxillin. 


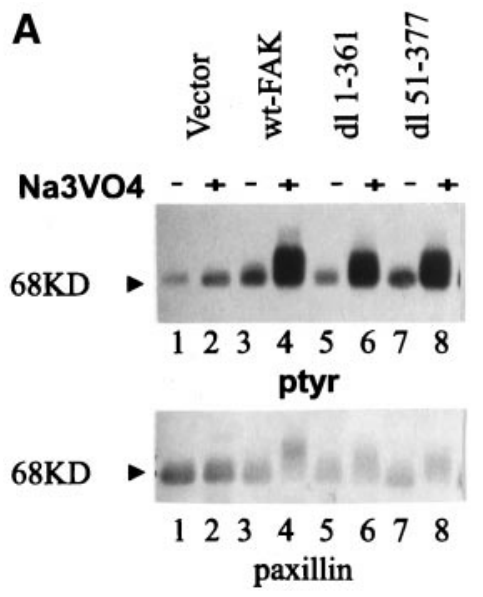

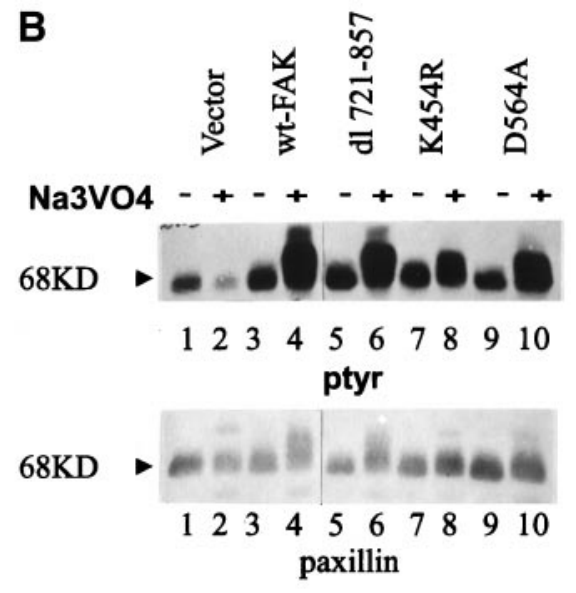

Figure 6. N-terminal deletion mutants can induce paxillin phosphorylation. (A) Cells transfected with empty RCAS (lanes 1 and 2) and cells expressing wild-type FAK (lanes 3 and 4), dl 1-361 (lanes 5 and 6), or dl 51-377 (lanes 7 and 8) were incubated overnight in the absence (lanes 1, 3, 5, and 7) or presence (lanes 2, 4, 6, and 8) of $50 \mu \mathrm{M}$ sodium vanadate. The cells were lysed, and paxillin was immunoprecipitated. The immune complexes were analyzed by Western blotting using an anti-phosphotyrosine antibody (top) and a paxillin monoclonal antibody (bottom). The arrowheads denote the position of the $68-\mathrm{kDa}$ marker. (B) Control transfected cells (lanes 1 and 2 ) and cells expressing wildtype FAK (lanes 3 and 4), dl 721-857 (lanes 5 and 6), FAK ${ }^{454 R}$ (K454R; lanes 7 and 8), or FAK ${ }^{564 A}$ (D564A; lanes 9 and 10) were incubated overnight in the absence (lanes 1, 3, 5, 7, and 9) or presence (lanes 2, 4, 6, 8, and 10) of $50 \mu \mathrm{M}$ sodium vanadate. Cells were lysed, and paxillin was immunoprecipitated and analyzed as described in A.

\section{Construction and Characterization of an FAK/Vinculin Chimera}

Because the FAT sequence of FAK was the major determinant in linking FAK to the integrins and to its downstream substrates, a strategy was devised to test whether focal adhesion targeting was sufficient for these functions. A chimeric molecule in which the FAT sequence of FAK was replaced with the $\mathrm{N}$-terminal focal adhesion-targeting sequence of vinculin was engineered. The $\mathrm{N}$-terminal domain of vinculin has been successfully used to target c-Src to focal adhesions (Liebl and Martin, 1992). This domain of vinculin was substituted for the C-terminal noncatalytic domain of FAK. In this chimera, residues 1-361 of FAK were not included because of the packaging limit of the expression vector. However, the deletion of these residues should not affect the function of the chimera because dl 1-361 behaves like wild-type FAK with respect to cell adhesion-dependent regulation and induction of paxillin phosphorylation (Figures 2 and 6). The chimera was expressed in CE cells using the RCAS A vector.

Expression of the FAK/vinculin chimera, called $\mathrm{FAK}^{\mathrm{F} / \mathrm{V}}$, was verified by immunoprecipitation and Western blotting using the polyclonal antiserum $\mathrm{BC} 2$, which recognizes the catalytic domain of FAK. As predicted, BC2 recognized an 86-kDa protein in lysates from cells expressing FAK $^{\mathrm{F}} / \mathrm{V}$ (Figure 7C). This protein was not detected in control cells transfected with the empty vector or in cells overexpressing wild-type FAK (which exhibits a 125-kDa BC2-reactive band). The subcellular localization of $\mathrm{FAK}^{\mathrm{F} / \mathrm{V}}$ was examined by immunofluorescence using BC2. The cells were costained with a monoclonal antibody against paxillin as a marker for focal adhesions. Under the staining conditions used, the signal attributable to endogenous FAK was very weak; thus exogenously expressed FAK could be distinguished from the endogenous wild-type protein (Figure 8, top right). Exogenously expressed wild-type FAK efficiently colocalized with paxillin in focal adhesions (Figure 8 , middle). FAK F/V $^{\mathrm{F}}$ also exhibited a typical focal adhesion localization (Figure 8, bottom right). Thus the focal adhesion-targeting sequence of vinculin could replace the FAT sequence of FAK and deliver the chimera to focal adhesions.
The enzymatic activity of $\mathrm{FAK}^{\mathrm{F} / \mathrm{V}}$ was examined in an immune complex PTK assay. Endogenous FAK, exogenously expressed wild-type FAK, or the chimera were immunoprecipitated from cell lysates using BC2 and assessed for autophosphorylation. Endogenous FAK exhibited a low level of activity because of the smaller amount of protein in the immune complex. Both wild-type FAK and the chimera exhibited comparable autophosphorylation, demonstrating that $\mathrm{FAK}^{\mathrm{F} / \mathrm{V}}$ was enzymatically active (Figure $7 \mathrm{~B}$ ). In addition to the major FAK and $\mathrm{FAK}^{\mathrm{F} / \mathrm{V}}$ signal, there were some lower molecular weight phosphorylated proteins in the FAK and $\mathrm{FAK}^{\mathrm{F} / \mathrm{V}}$ immune complexes. These could be either degradation products or proteins that associate with FAK or $\mathrm{FAK}^{\mathrm{F} / \mathrm{V}}$. Tyrosine phosphorylation of $\mathrm{FAK}^{\mathrm{F} / \mathrm{V}}$ in subconfluent cells was examined by immunoprecipitation with BC2 and Western blotting. Like exogenously expressed wild-type FAK, the chimera was phosphorylated on tyrosine (Figure 9).

\section{FAK ${ }^{F / V}$ Is Regulated by Cell Adhesion and Can Induce Paxillin Phosphorylation}

The integrin-dependent tyrosine phosphorylation of $\mathrm{FAK}^{\mathrm{F} / \mathrm{V}}$ was tested by detaching cells from the extracellular matrix and replating onto fibronectin- or poly-L-lysinecoated plates. The phosphotyrosine content of the chimera decreased upon trypsinization and incubation in suspension. After the cells were plated on fibronectin, an increase in tyrosine phosphorylation of $\mathrm{FAK}^{\mathrm{F} / \mathrm{V}}$ was observed (Figure 9A, top). In contrast, cell adhesion to poly-L-lysine did not result in increased tyrosine phosphorylation of $\mathrm{FAK}^{\mathrm{F} / \mathrm{V}}$. A control Western blot using BC2 verified that the differences seen in the anti-phosphotyrosine blot were not caused by the differences in the amount of protein recovered (Figure 9A, bottom). This result demonstrates that tyrosine phosphorylation of $\mathrm{FAK}^{\mathrm{F} / \mathrm{V}}$ is regulated like that of wild-type FAK, suggesting that focal adhesion targeting is sufficient for the cell adhesion-dependent regulation of FAK.

The ability of the chimera to signal downstream was also examined. Initially the phosphotyrosine profile of cellular proteins was examined by Western-blotting whole-cell ly- 
A

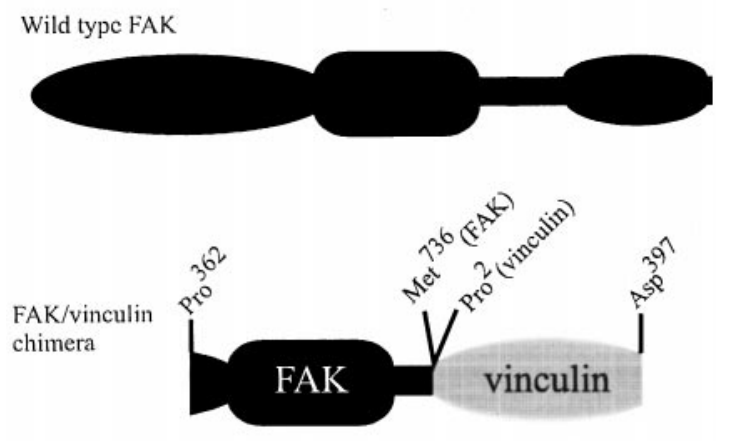

B

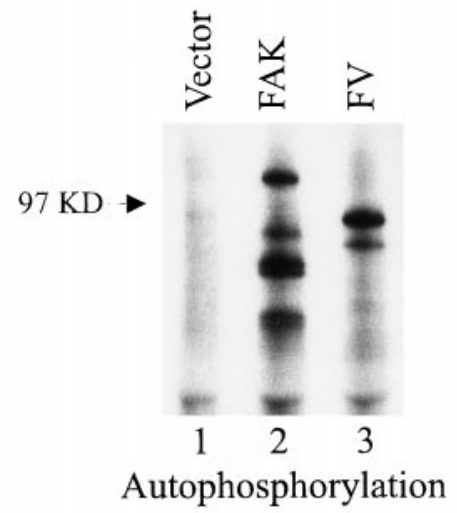

C

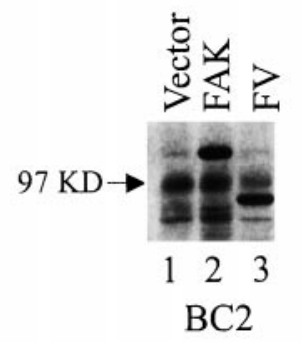

Figure 7. Expression and catalytic activity of an FAK/vinculin chimera. (A) A diagram of wild-type FAK and the FAK/vinculin chimera is shown. An initiation codon and epitope tag were fused in-frame with the FAK sequences beginning at codon 362. A termination codon was engineered immediately following codon 397 of the vinculin sequence. (B and C) CE cells transfected with empty RCAS (lane 1) or RCAS containing the sequences encoding wild-type FAK (lane 2) or the FAK/vinculin chimera (FV; lane 3) were lysed, and immunoprecipitations were performed using the $\mathrm{BC} 2$ polyclonal antiserum. Onehalf of each immunocomplex was analyzed by Western blotting using BC2. (C) The other one-half was incubated in an in vitro protein tyrosine kinase assay for $15 \mathrm{~min}$ in the presence of $\left[\gamma^{-32} \mathrm{P}\right] \mathrm{ATP}$. Kinase reactions were terminated by adding an equal volume of $2 \times$ Laemmli sample buffer (Laemmli, 1970). The samples were analyzed by SDSPAGE and autoradiography (B, exposure time of $1 \mathrm{~h}$ ). The arrowheads indicate the position of the 97-kDa molecular weight marker.

sates. Wild-type FAK-expressing cells contained a prominent $125-\mathrm{kDa}$ phosphotyrosine-containing protein, which was the exogenously expressed FAK. These cells also exhib- ited a very modest increase in the phosphotyrosine content of paxillin (seen as a 65- to 70-kDa band in the phosphotyrosine blot). In lysates of cells expressing $\mathrm{FAK}^{\mathrm{F} / \mathrm{V}}$, a novel 86-kDa phosphotyrosine-containing protein was evident, which was the chimera itself. Expression of $\mathrm{FAK}^{\mathrm{F} / \mathrm{V}}$ did not perceptibly alter the phosphotyrosine content of any cellular protein. However, when wild-type FAK- or $\mathrm{FAK}^{\mathrm{F} / \mathrm{V}}$-expressing cells, but not cells transfected with the empty RCAS vector, were treated with vanadate, there was a profound increase in the phosphotyrosine content of a number of cellular proteins. Although the induction of tyrosine phosphorylation by $\mathrm{FAK}^{\mathrm{F} / \mathrm{V}}$ was less dramatic than that by wildtype FAK, a similar pattern of tyrosine-phosphorylated proteins was seen (Figure 9C). Tyrosine phosphorylation of paxillin was specifically examined by immunoprecipitation and Western blotting. Vanadate treatment of both FAK- and $\mathrm{FAK}^{\mathrm{F} / \mathrm{V}}$-expressing CE cells induced a dramatic increase in the phosphotyrosine content of paxillin (Figure 9B). Thus $\mathrm{FAK}^{\mathrm{F} / \mathrm{V}}$ behaves like wild-type FAK and induces tyrosine phosphorylation of paxillin.

The major site of autophosphorylation of wild-type FAK is tyrosine 397. Upon phosphorylation of this site, FAK binds Src family PTKs via SH3- and SH2-mediated interactions to form signaling complexes. The ability of $\mathrm{FAK}^{\mathrm{F} / \mathrm{V}}$ to associate with Src family PTKs was examined by coimmunoprecipitation and Western blotting. Because endogenous FAK coimmunoprecipitated with endogenous Fyn from CE cell lysates (Cobb et al., 1994), the interaction of FAK and $\mathrm{FAK}^{\mathrm{F} / \mathrm{V}}$ with Fyn was examined. Endogenous Fyn was immunoprecipitated from lysates of CE cells expressing FAK or $\mathrm{FAK}^{\mathrm{F} / \mathrm{V}}$, and the immune complexes were blotted with $\mathrm{BC} 2$. Both exogenously expressed FAK and $\mathrm{FAK}^{\mathrm{F} / \mathrm{V}}$ were detected in the Fyn immune complexes (Figure 10A) (at the level of exposure of the blot endogenous FAK cannot be detected). Therefore, like wild-type FAK, FAK ${ }^{\mathrm{F} / \mathrm{V}}$ has the capacity to associate with Src family PTKs. To characterize the chimera further, we coexpressed Fyn and $\mathrm{FAK}^{\mathrm{F} / \mathrm{V}}$ in $\mathrm{CE}$ cells. Upon coexpression, both wild-type FAK and FAK ${ }^{\mathrm{F} / \mathrm{V}}$ could be coimmunoprecipitated with exogenously expressed Fyn (our unpublished results). As described above, expression of FAK or $\mathrm{FAK}^{\mathrm{F} / \mathrm{V}}$ alone induced modest changes in the phosphotyrosine levels of cellular proteins. Likewise, expression of Fyn alone only induced modest changes in phosphotyrosine. Coexpression of either wildtype FAK or $\mathrm{FAK}^{\mathrm{F} / \mathrm{V}}$ with fyn induced a dramatic increase in tyrosine phosphorylation of paxillin (Figure 10B). These results demonstrate that the FAK/vinculin chimera behaves like wild-type FAK both in its capacity to associate with Src family PTKs and in its ability to induce tyrosine phosphorylation of paxillin in vivo.

\section{DISCUSSION}

A mutational strategy was applied to determine the importance of different domains of FAK in regulating its tyrosine phosphorylation after integrin-dependent cell adhesion. The results indicate that neither the $\mathrm{N}$-terminal domain nor the region between the catalytic domain and the FAT sequence is required for cell adhesion-dependent FAK phosphorylation. Furthermore, these regions are dispensable for the FAK-dependent induction of tyrosine phosphorylation of paxillin. The FAT sequence of FAK is the single critical 


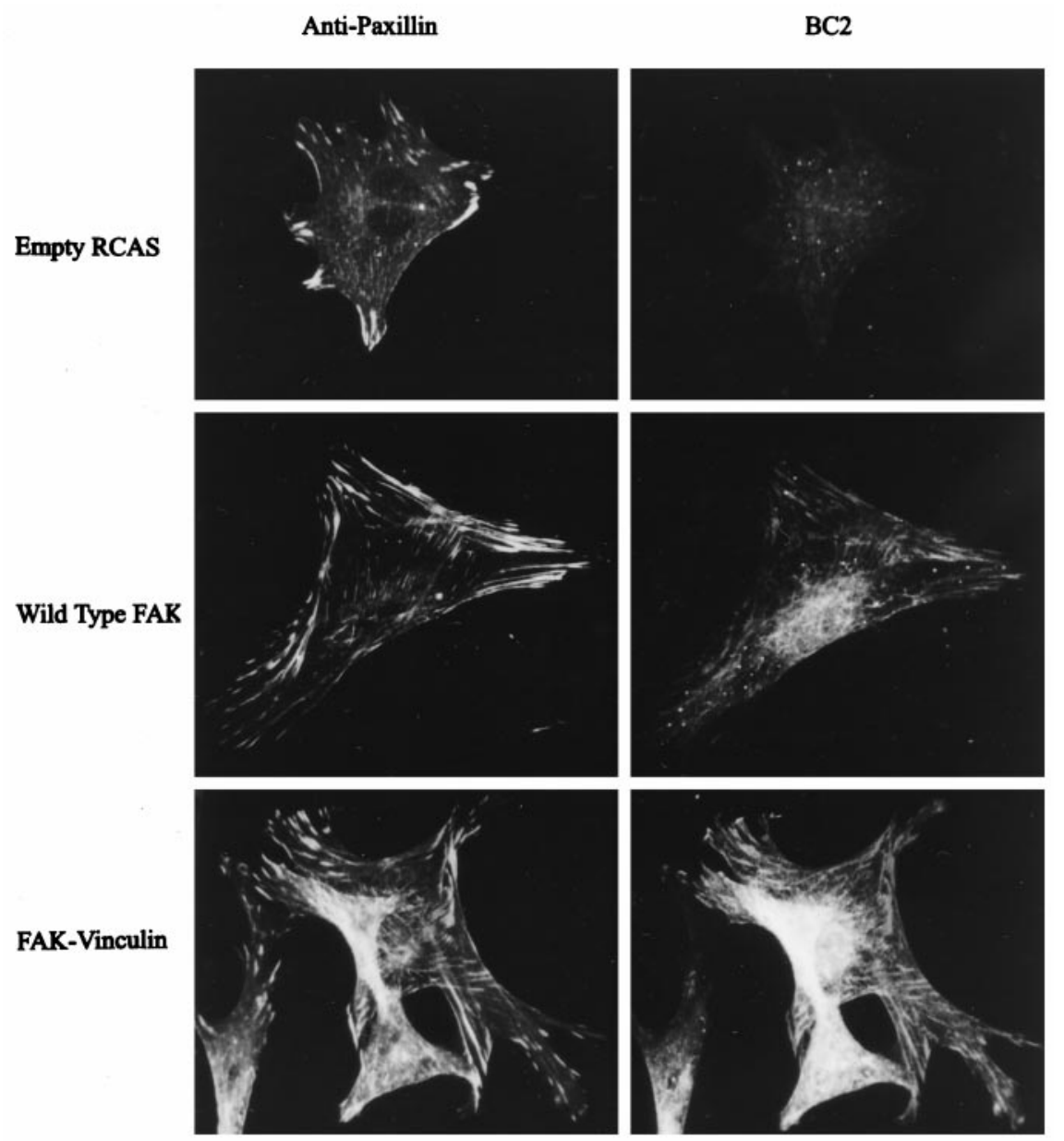

Figure 8. Subcellular localization of the FAK/vinculin chimera. Cells transfected with empty RCAS (top) and cells expressing wild-type FAK (middle) or the FAK/vinculin chimera (bottom) were fixed and stained using purified BC2 (right). Cells were costained using a paxillin monoclonal antibody (left). domain for both integrin-dependent tyrosine phosphorylation and downstream signaling. Furthermore, focal adhesion localization is apparently sufficient for cell adhesion-dependent regulation and downstream signaling, because an FAK/vinculin chimera, which targets to focal adhesions via vinculin sequences rather than the FAT sequence, exhibits properties similar to those of wild-type FAK.

The integrin-dependent regulation of FAK was proposed to occur via a direct interaction between the N-terminal domain of FAK and the cytoplasmic domain of the integrin $\beta$ subunit. The $\mathrm{N}$-terminus of FAK can bind to peptides corresponding to the integrin cytoplasmic domain in vitro (Schaller et al., 1995). Furthermore, FAK can become clustered and tyrosine phosphorylated after cross-linking unoccupied integrins, conditions in which other cytoskeletal proteins are not clustered (Miyamoto et al., 1995). These results are consistent with this model. However, other data clearly disprove this hypothesis. The analysis of splicing variants of the $\beta_{1}$ integrin subunit and mutational analyses of both $\beta_{1}$ and $\beta_{3}$ integrin subunits do not support this model. There are mutants and/or splicing variants of the $\beta_{1}$ and $\beta_{3}$ integrin subunits that retain the putative FAK-binding site yet fail to induce tyrosine phosphorylation of FAK (Akiyama et al., 1994; Balzac et al., 1994; Tahiliani et al., 1997). Conversely, there are integrin mutants that have perturbations in the putative FAK-binding site yet are as capable as wild-type integrins at inducing tyrosine phosphorylation of FAK (Lyman et al., 1997; Tahiliani et al., 1997). Consistent with these findings, our results directly demonstrate that the N-terminal, integrin-binding domain of FAK is dispensable for cell adhesion-dependent tyrosine phosphorylation. This domain is also not required for the induction of tyrosine phosphorylation of paxillin. Although the role of an integrin/ FAK interaction remains open to speculation, it clearly makes a minor, if any, contribution to the integrin-dependent regulation of FAK or to directing the FAKdependent phosphorylation of other cellular proteins.

The importance of the FAT sequence in the response of FAK to cell adhesion is evident from our studies. Two mutants with partial deletions of the FAT sequence, which do not localize to focal adhesions, do not behave like wildtype FAK when cells are detached from their substrate and allowed to readhere to fibronectin. Both dl 853-963 and dl 965-1012 are tyrosine phosphorylated in subconfluent growing cells. The phosphotyrosine content of dl 853-963 declines when cells are detached, but the mutant fails to become tyrosine phosphorylated after plating the cells on fibronectin for up to $3 \mathrm{~h}$. dl 965-1012 exhibits a delay in dephosphorylation when cells are detached. After dephosphorylation occurs, dl 965-1012 is also defective for cell 

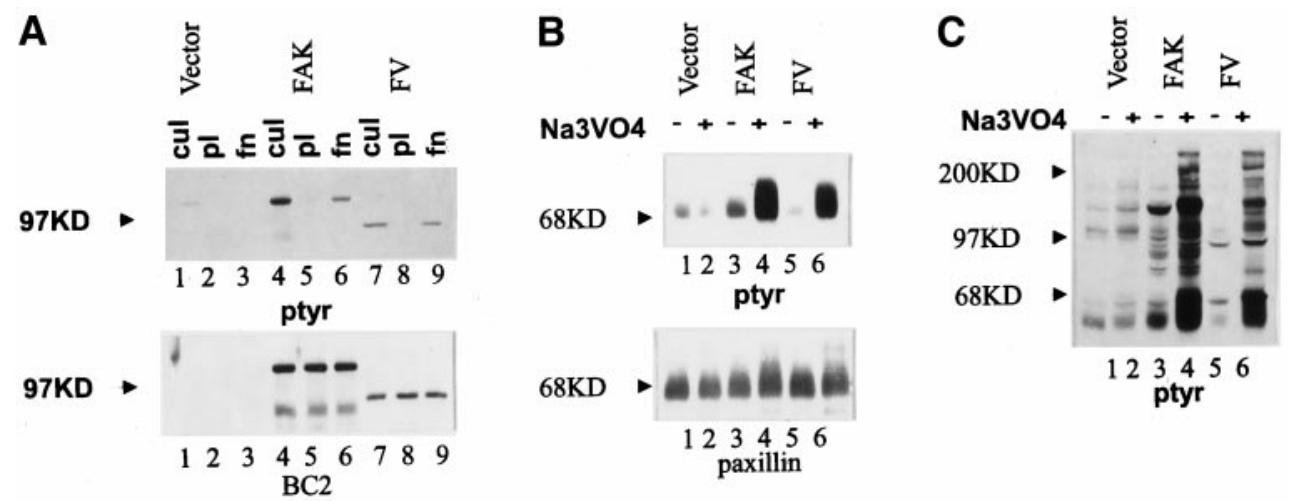

Figure 9. The FAK/vinculin chimera functions like wild-type FAK. (A) Cells transfected with empty RCAS (lanes 1-3) and cells expressing wild-type FAK (lanes 4-6) or FAK $\mathrm{F}^{\mathrm{F}} \mathrm{V}$ (lanes 7-9) were analyzed. Lysates of cultured cells (lanes 1, 4, and 7) or cells plated on poly-L-lysinecoated plates (lanes 2, 5, and 8) or fibronectin-coated plates (lanes 3, 6, and 9) were immunoprecipitated with BC2. The immune complexes were analyzed by Western blotting using an anti-phosphotyrosine antibody (top) or BC2 (bottom). The position of the 97-kDa molecular weight marker is shown by the arrowheads. (B and C) Control cells transfected with empty RCAS (lanes 1 and 2) and cells expressing wild-type FAK (lanes 3 and 4) or FAK ${ }^{\mathrm{F} / \mathrm{V}}$ (lanes 5 and 6 ) were incubated overnight in the absence (lanes 1,3 , and 5) or presence (lanes 2,4 , and 6) of $50 \mu \mathrm{M}$ sodium vanadate. (B) The cells were lysed, and paxillin was immunoprecipitated using a monoclonal antibody. The immune complexes were analyzed by Western blotting for phosphotyrosine (top) and for paxillin (bottom). The position of the 68-kDa molecular weight marker is indicated by the arrowheads. (C) The cells were lysed, and equivalent amounts of whole-cell lysate were directly analyzed by Western blotting for phosphotyrosine. The positions of the 200-, 97-, and 68-kDa molecular weight markers are shown by arrowheads.

adhesion-dependent tyrosine phosphorylation. The mechanism by which mutants that fail to target to focal adhesions become tyrosine phosphorylated is not clear, but we have eliminated the possibilities that they exhibit delayed responses to cell adhesion or are responsive to serum.

The delay in the dephosphorylation of dl 965-1012 when cells are taken into suspension is intriguing. Because this mutant is not hyperactive in an in vitro kinase activity (Hildebrand et al., 1993), we speculate that dl 965-1012 is defective for dephosphorylation upon cell detachment. This could be a consequence of phosphorylation on unique tyrosine residues that are suboptimal substrates for the phos- phatase that normally dephosphorylates FAK. Alternatively the mutant may fail to associate with the protein tyrosine phosphatase (PTP) responsible for FAK dephosphorylation. PTP-PEST has been shown to bind to FAK through paxillin (Shen et al., 1998). However, dl 853-963, dl 965-1012, and tagged wild-type FAK all fail to associate with PTP-PEST (and paxillin) (Shen et al., 1998). Because the dephosphorylation of tagged wild-type FAK and dl 853-963 appears to be normal, the defective dephosphorylation of dl 965-1012 cannot be explained by its failure to associate with PTP-PEST. Shp-2, an SH2 domain-containing PTP, has been reported to coimmunoprecipitate with FAK (Yu et al., 1998). Further-
Figure 10. $\mathrm{FAK}^{\mathrm{F} / \mathrm{V}}$ associates with Fyn and induces tyrosine phosphorylation of paxillin. (A) CE cells transfected with the RCAS A vector (lane 1) and cells expressing wild-type FAK (lane 2) or $\mathrm{FAK}^{\mathrm{F} / \mathrm{V}}$ (lane 3) were lysed, and endogenous Fyn was immunoprecipitated using a polyclonal antibody. Coimmunoprecipitating FAK or $\mathrm{FAK}^{\mathrm{F} / \mathrm{V}}$ was detected by Western blotting using BC2. (B) CE cells transfected with the RCAS A vector (lane 1 ), cells expressing exogenous Fyn (lane 2), wildtype FAK (lane 3), or FAK ${ }^{\mathrm{F} / \mathrm{V}}$ alone (lane 5), or cells coexpressing Fyn and FAK (lane 4) or Fyn and $\mathrm{FAK}^{\mathrm{F} / \mathrm{V}}$ (lane 6) were lysed, and paxillin was immunoprecipitated. The immune complexes were analyzed by Western blotting for phosphotyrosine (top) and for paxillin (bottom). The position of the $68-\mathrm{kDa}$ molecular weight marker is indicated by the arrowheads. I.P., Immunoprecipitate.

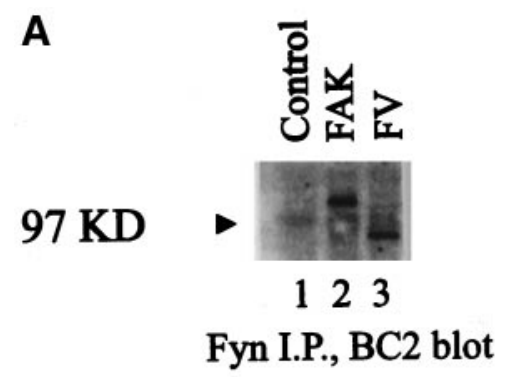

B
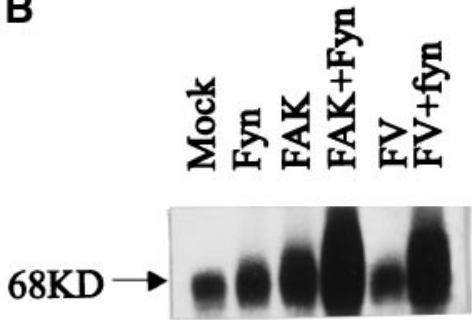
$\begin{array}{llllll}1 & 2 & 3 & 4 & 5 & 6\end{array}$

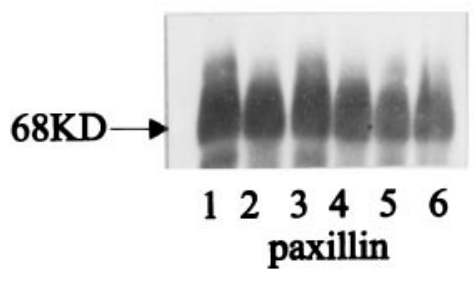


more, in shp-2-1- fibroblasts, FAK exhibits elevated phosphotyrosine levels when the cells are held in suspension ( $\mathrm{Yu}$ et al., 1998). Although these results suggest that dl 965-1012 may be defective in associating with Shp-2 or serving as its substrate, we have been unable to coimmunoprecipitate wild-type FAK with Shp-2 (or Shp-2 with FAK) from CE cell lysates (Schaller, unpublished observations). This has precluded directly testing the hypothesis that dl 965-1012 is defective for Shp-2 binding. Another candidate PTP that may regulate FAK phosphorylation is PTEN, a dual-specificity phosphatase that has been shown to induce dephosphorylation of FAK when expressed in fibroblasts (Tamura et al., 1998). Circumstantial evidence suggests that two other PTPs could function in regulating FAK dephosphorylation. These are PTP1B, which binds to and regulates tyrosine phosphorylation of $\mathrm{p} 130^{\text {cas }}$ (an FAK-binding partner) (Liu et al., 1996), and LAR, which can localize to focal adhesions (Serra-Pages et al., 1995), The role of each of these phosphatases in regulating the dephosphorylation of FAK and the mechanism by which the enzyme(s) is targeted to FAK remain to be firmly established.

It is not surprising that the C-terminal FAT sequence is necessary for integrin-dependent regulation because it is required for focal adhesion targeting and hence colocalization with integrins. However, it was unanticipated that the FAT sequence would be the single major determinant in cell adhesion-dependent regulation. This result suggests two models. First, subcellular localization mediated by the FAT sequence is sufficient to confer adhesion-dependent regulation of FAK. Second, the C-terminal domain of FAK might fulfill two independent functions: 1) targeting to focal adhesions and 2) regulation of catalytic activity and/or tyrosine phosphorylation. We favor the first hypothesis because the FAT sequence can be functionally replaced with a focal adhesion-targeting sequence from vinculin. It seems extremely unlikely that the heterologous vinculin sequences could replace a regulatory function. However, further mutational analysis of the FAT sequence of FAK will be required to distinguish conclusively between these possibilities. The FAT sequence of FAK contains binding sites for both paxillin and talin. Likewise, vinculin contains binding sites for both paxillin and talin. The talin-binding site is in the N-terminal region of vinculin, whereas the paxillin-binding site is in the C-terminus (Gilmore et al., 1992; Wood et al., 1994). Thus $\mathrm{FAK}^{\mathrm{F} / \mathrm{V}}$ contains the talin-binding site but not the paxillin-binding site of vinculin. The epitope-tagged FAK construct used in this analysis is defective for paxillin binding (Hildebrand et al., 1995) (yet correctly localizes to focal adhesions [Hildebrand et al., 1993; Schaller et al., 1993; Schaller and Sasaki, 1997]). Because both tagged FAK and $\mathrm{FAK}^{\mathrm{F} / \mathrm{V}}$ are regulated in a cell adhesion-dependent manner, paxillin binding seems dispensable for FAK regulation. The successful replacement of the FAT sequence of FAK with vinculin sequences may indicate that targeting to focal adhesions in general is sufficient for FAK function. Alternatively, this result might also indicate that FAK must bind to talin to function. Further experimentation will be required to distinguish between these models.

FAK-dependent tyrosine phosphorylation of tensin and paxillin can be induced by treatment of FAK-overexpressing CE cells with vanadate or by coexpression of FAK with Src family PTKs (Schaller and Parsons, 1995; Schaller and
Sasaki, 1997; Thomas et al., 1998). FAK mutants that fail to target to focal adhesions are defective for inducing tyrosine phosphorylation of these substrates (Schaller and Parsons, 1995). Our deletion analysis has failed to identify any additional sequences of FAK that are required for the induction of tyrosine phosphorylation of paxillin. Furthermore, replacement of the FAT sequence of FAK with a heterologous focal adhesion-targeting sequence did not alter the ability of the chimera to induce paxillin phosphorylation after vanadate treatment or the coexpression with Src family PTKs. Therefore it appears that the major determinant in FAKdependent tyrosine phosphorylation of paxillin is the ability of FAK to target to focal adhesions and/or bind talin. Interestingly, two catalytic defective mutants of FAK can induce tyrosine phosphorylation of paxillin upon vanadate treatment of CE cells. Similarly, these mutants can induce tyrosine phosphorylation upon coexpression with Src family PTKs (Schaller, unpublished observations). Because FAK ${ }^{397 \mathrm{~F}}$ is unable to induce paxillin phosphorylation in these assays, recruitment of Src PTKs is essential for the induction of paxillin. Therefore it is likely that the catalytically inactive FAK mutants recruit Src family PTKs to phosphorylate paxillin. The observation that catalytically inactive FAK mutants can induce tyrosine phosphorylation of cellular proteins in vivo is consistent with the observations that these mutants can also function biologically in some assays. Overexpression of FAK increases the motility of Chinese hamster ovary cells and in CE cells can overcome the inhibition of cell spreading by a dominant-negative FAK construct called FAK-related nonkinase (Cary et al., 1996; Richardson et al., 1997). Catalytically inactive FAK functions similar to wildtype FAK in both of these assays. In each of these biological assays FAK ${ }^{397 F}$ is completely defective. These observations are consistent with the hypothesis that recruitment of Src family PTKs is important for FAK function.

In summary, our collective evidence indicates that there are two crucial regions of FAK required for cell adhesiondependent regulation and the transmission of downstream signals. First, tyrosine 397, the major autophosphorylation and Src SH2-binding site, is required for both functions. Second, the focal adhesion-targeting sequence is necessary for both integrin-induced tyrosine phosphorylation of FAK and induction of tyrosine phosphorylation of substrates like paxillin. Thus a key feature engendering FAK with its functions is its ability to localize to focal adhesions.

\section{ACKNOWLEDGMENTS}

We gratefully acknowledge the gifts of a vinculin cDNA from Dr. David Critchley, FAK mutants and polyclonal antiserum from Dr. Tom Parsons, and a Fyn polyclonal antiserum from Dr. Andre Veillette. The comments of Dr. Keith Burridge during the course of this investigation were invaluable to its progress. We also thank Jill Broome. The research was funded by a grant from the American Cancer Society (RPG-96-021-03-CSM).

\section{REFERENCES}

Abedi, H., Dawes, K.E., and Zachary, I. (1995). Differential effects of platelet-derived growth factor BB on p125 focal adhesion kinase and paxillin tyrosine phosphorylation and on cell migration in rabbit aortic vascular smooth muscle cells and Swiss 3T3 fibroblasts. J. Biol. Chem. 270, 11367-11376. 
Akiyama, S.K., Yamada, S.S., Yamada, K.M., and LaFlamme, S.E. (1994). Transmembrane signal transduction by integrin cytoplasmic domains expressed in single-subunit chimeras. J. Biol. Chem. 269, 15961-15964.

Assoian, R.A., and Zhu, X. (1997). Cell anchorage and the cytoskeleton as partners in growth factor dependent cell cycle progression. Curr. Opin. Cell Biol. 9, 93-98.

Balzac, F., Retta, S.F., Albini, A., Melchiorri, A., Koteliansky, V.E., Geuna, M., Silengo, L., and Tarone, G. (1994). Expression of beta 1B integrin isoform in $\mathrm{CHO}$ cells results in a dominant negative effect on cell adhesion and motility. J. Cell Biol. 127, 557-565.

Barry, S.T., and Critchley, D.R. (1994). The RhoA-dependent assembly of focal adhesions in Swiss 3T3 cells is associated with increased tyrosine phosphorylation and the recruitment of both $\mathrm{pp} 125^{\mathrm{FAK}}$ and protein kinase C-delta to focal adhesions. J. Cell Sci. 107, 2033-2045.

Brinson, A.E., Harding, T., Diliberto, P.A., He, Y., Li, X., Hunter, D., Herman, B., Earp, H.S., and Graves, L.M. (1998). Regulation of a calcium-dependent tyrosine kinase in vascular smooth muscle cells by angiotensin II and platelet-derived growth factor. Dependence on calcium and the actin cytoskeleton. J. Biol. Chem. 273, 1711-1718.

Brooks, P.C., Clark, R.A.F., and Cheresh, D.A. (1994). Requirement of vascular integrins alpha V beta 3 for angiogenesis. Science 264 $569-571$.

Burridge, K., Turner, C.E., and Romer, L.H. (1992). Tyrosine phosphorylation of paxillin and pp $125^{\mathrm{FAK}}$ accompanies cell adhesion to extracellular matrix: a role in cytoskeletal assembly. J. Cell Biol. 119, 893-903.

Calalb, M.B., Polte, T.R., and Hanks, S.K. (1995). Tyrosine phosphorylation of focal adhesion kinase at sites in the catalytic domain regulates kinase activity: a role for src family kinases. Mol. Cell. Biol. $15,954-963$.

Cary, L.A., Chang, J.F., and Guan, J.L. (1996). Stimulation of cell migration by overexpression of focal adhesion kinase and its association with src and fyn. J. Cell Sci. 109, 1787-1794.

Catling, A.D., Wyke, J.A., and Frame, M.C. (1993). Mitogenesis of quiescent chick fibroblasts by $\mathrm{v}$-src: dependence on events at the membrane leading to early changes in AP-1. Oncogene 8, 1875-1886.

Chen, H.-C., Appeddu, P.A., Parsons, J.T., Hildebrand, J.D., Schaller, M.D., and Guan, J.-L. (1995). Interaction of FAK with cytoskeletal protein talin. J. Biol. Chem. 270, 16995-16999.

Chrzanowska-Wodnicka, M., and Burridge, K. (1994). Tyrosine phosphorylation is involved in reorganization of the actin cytoskeleton in response to serum or LPA stimulation. J. Cell Sci. 107, 3643-3654.

Clark, E.A., Shattil, S.J., Ginsberg, M.H., Bolen, J., and Brugge, J.S. (1994). Regulation of the protein tyrosine kinase $\mathrm{pp} 72^{\text {syk }}$ by platelet agonists and the integrin alpha $\mathrm{IIb}_{\mathrm{Ib}}$ beta $_{3}$. J. Biol. Chem. 269, 2885928864 .

Cobb, B.S., Schaller, M.D., Leu, T.-H., and Parsons, J.T. (1994). Stable association of $\mathrm{pp} 60^{\mathrm{src}}$ and $\mathrm{p} 59^{\mathrm{fyn}}$ with the focal adhesion-associated kinase, pp125 ${ }^{\text {FAK }}$. Mol. Cell. Biol. 14, 147-155.

Faraldo, M.M., Deugnier, M.A., Lukashev, M., Thiery, J.P., and Glukhova, M.A. (1998). Perturbation of beta 1-integrin function alters the development of murine mammary gland. EMBO J. 17, $2139-2147$.

Friedlander, M., Brooks, P.C., Shaffer, R.W., Kincade, C.M., Varner, J.A., and Cheresh, D.A. (1995). Definition of two angiogenic pathways by distinct alpha V integrins. Science 270, 1500-1502.

Frisch, S.M., and Francis, H. (1994). Disruption of epithelial cellmatrix interaction induces apoptosis. J. Cell Biol. 124, 619-626.
Frisch, S.M., Vuori, K., Ruoslahti, E., and Chan-Hui, P.-Y. (1996). Control of adhesion-dependent cell survival by focal adhesion kinase. J. Cell Biol. 134, 793-799.

Gilmore, A., and Romer, L.H. (1996). Inhibition of FAK signaling in focal adhesions decreases cell motility and proliferation. Mol. Biol. Cell 7, 1209-1224.

Gilmore, A.P., Jackson, P., Waites, G.T., and Critchley, D.R. (1992). Further characterization of the talin-binding site in the cytoskeletal protein vinculin. J. Cell Sci. 103, 719-731.

Guan, J.-L., and Shalloway, D. (1992). Regulation of pp125 12 FAK both by cellular adhesion and by oncogenic transformation. Nature 358, 690-692.

Hanks, S.K., Calalb, M.B., Harper, M.C., and Patel, S.K. (1992). Focal adhesion protein tyrosine kinase phosphorylated in response to cell spreading on fibronectin. Proc. Natl. Acad. Sci. USA 89, 8487-8489.

Harte, M.T., Hildebrand, J.D., Burnham, M.R., Bouton, A.H., and Parsons, J.T. (1996). p130 cas, a substrate associated with v-src and $\mathrm{v}$-crk, localizes to focal adhesions and binds to focal adhesion kinase. J. Biol. Chem. 271, 13649-13655.

Hildebrand, J.D., Schaller, M.D., and Parsons, J.T. (1993). Identification of sequences required for the efficient localization of the focal adhesion kinase, pp125 $5^{\mathrm{FAK}}$, to cellular focal adhesions. J. Cell Biol. 123, 993-1005.

Hildebrand, J.D., Schaller, M.D., and Parsons, J.T. (1995). Paxillin, a tyrosine phosphorylated focal adhesion-associated protein binds to the carboxyl terminal domain of focal adhesion kinase. Mol. Biol. Cell 6, 637-647.

Hildebrand, J.D., Taylor, J.M., and Parsons, J.T. (1996). An SH3 domain-containing GTPase-activating protein for rho and cdc42 associates with focal adhesion kinase. Mol. Cell. Biol. 16, 3169-3178.

Hungerford, J.E., Compton, M.T., Matter, M.L., Hoffstrom, B.G., and Otey, C.A. (1996). Inhibition of pp125FAK in cultured fibroblasts results in apoptosis. J. Cell Biol. 135, 1383-1390.

Hynes, R.O. (1992). Integrins: versatility, modulation, and signaling in cell adhesion. Cell 69, 11-25.

Ilic, D., et al. (1995). Reduced cell motility and enhanced focal adhesion contact formation in cells from FAK-deficient mice. Nature $377,539-544$.

Jones, J.I., Doerr, M.E., and Clemmons, D.R. (1995). Cell migration: interactions among integrins, IGFs and IGFBPs. Prog. Growth Factor Res. 6, 319-327.

King, W.G., Mattaliano, M.D., Chan, T.O., Tsichlis, P.N., and Brugge, J.S. (1997). Phosphatidylinositol 3-kinase is required for integrin-stimulated AKT and Raf- $1 /$ mitogen-activated protein kinase pathway activation. Mol. Cell. Biol. 17, 4406-4418.

Laemmli, U.K. (1970). Cleavage of structural proteins during assembly of the head of bacteriophage T4. Nature 227, 680-685.

Lewis, J.M., Baskaran, R., Taagepera, S., Schwartz, M.A., and Wang, J.Y.J. (1996). Integrin regulation of c-Abl tyrosine kinase activity and cytoplasmic-nuclear transport. Proc. Natl. Acad. Sci. USA 93, 15174-15179.

Li, J., Avraham, H., Rogers, R.A., Raja, S., and Avraham, S. (1996). Characterization of RAFTK, a novel focal adhesion kinase, and its integrin-dependent phosphorylation and activation in megakaryocytes. Blood 88, 417-428.

Liebl, E.C., and Martin, G.S. (1992). Intracellular targeting of pp60src expression: localization of $\mathrm{v}$-src to focal adhesion plaques is sufficient to transform chicken embryo fibroblast. Oncogene 7, 24172428.

Lin, T.H., Rosales, C., Mondal, K., Bolen, J.B., Haskill, S., and Juliano, R.L. (1995). Integrin-mediated tyrosine phosphorylation 
and cytokine message induction in monocytic cells. A possible signaling role for the Syk tyrosine kinase. J. Biol. Chem. 270, 1618916197.

Lipfert, L., Haimovich, B., Schaller, M.D., Cobb, B.S., Parsons, J.T., and Brugge, J.S. (1992). Integrin-dependent phosphorylation and activation of the protein tyrosine kinase $\mathrm{pp} 125^{\mathrm{FAK}}$ in platelets. J. Cell Biol. 119, 905-912.

Liu, F., Hill, D.E., and Chernoff, J. (1996). Direct binding of the proline-rich region of protein tyrosine phosphatase $1 \mathrm{~B}$ to the src homology 3 domain of p130CAS. J. Biol. Chem. 271, 31290-31295.

Lyman, S., Gilmore, A., Burridge, K., Gidwitz, S., and White, G.C., II (1997). Integrin-mediated activation of focal adhesion kinase is independent of focal adhesion formation or integrin activation. Studies with activated and inhibitory beta 3 cytoplasmic domain mutants. J. Biol. Chem. 272, 22538-22547.

MacArthur, H., and Walter, G. (1984). Monoclonal antibodies specific for the carboxyl terminus of SV40 large T antigen. J. Virol. 52, 483-491.

Meredith, J.E., and Schwartz, M.A. (1993). The extracellular matrix as a cell survival factor. Mol. Biol. Cell 4, 953-961.

Miyamoto, S., Akiyama, S.K., and Yamada, K.M. (1995). Synergistic roles for receptor occupancy and aggregation in integrin transmembrane function. Science 267, 883-885.

Polte, T.R., and Hanks, S.K. (1995). Interaction between focal adhesion kinase and crk-associated kinase substrate p130 cas. Proc. Natl. Acad. Sci. USA 92, 10678-10685.

Rankin, S., and Rozengurt, E. (1994). Platelet-derived growth factor modulation of focal adhesion kinase $\left(\mathrm{p} 125^{\mathrm{FAK}}\right)$ and paxillin tyrosine phosphorylation in Swiss 3T3 cells. J. Biol. Chem. 269, 704-710.

Reynolds, A.B., Roesel, D.J., Kanner, S.B., and Parsons, J.T. (1989). Transformation-specific tyrosine phosphorylation of a novel cellular protein in chicken cells expressing oncogenic variants of the avian cellular src gene. Mol. Cell. Biol. 9, 629-638.

Richardson, A., Malik, R.K., Hildebrand, J.H., and Parsons, J.T. (1997). Inhibition of cell spreading by expression of the C-terminal domain of focal adhesion kinase (FAK) is rescued by coexpression of Src or catalytically inactive FAK: a role for paxillin tyrosine phosphorylation. Mol. Cell. Biol. 17, 6906-6914.

Richardson, A., and Parsons, J.T. (1996). A mechanism for regulation of the focal adhesion-associated protein tyrosine kinase. Nature 380, 538-540.

Romer, L.H., McLean, N., Turner, C.E., and Burridge, K. (1994). Tyrosine kinase activity, cytoskeletal organization, and motility in human vascular endothelial cells. Mol. Biol. Cell 5, 349-361.

Schaller, M.D., Borgman, C.A., Cobb, B.S., Vines, R.R., Reynolds, A.B., and Parsons, J.T. (1992). pp $125^{\mathrm{FAK}}$, a structurally distinctive protein tyrosine kinase associated with focal adhesions. Proc. Natl. Acad. Sci. USA 89, 5192-5196.

Schaller, M.D., Borgman, C.A., and Parsons, J.T. (1993). Autonomous expression of a noncatalytic domain of the focal adhesion associated protein tyrosine kinase pp125 ${ }^{\mathrm{FAK}}$. Mol. Cell. Biol. 13, 785-791.

Schaller, M.D., Hildebrand, J.D., Shannon, J.D., Fox, J.W., Vines, R.R., and Parsons, J.T. (1994). The autophosphorylation site of the focal adhesion kinase, pp $125^{\mathrm{FAK}}$ : a high affinity binding site for pp60 ${ }^{\text {src }}$. Mol. Cell. Biol. 14, 1680-1688.

Schaller, M.D., Otey, C.A., Hildebrand, J.D., and Parsons, J.T. (1995). pp $125^{\mathrm{FAK}}$ and paxillin physically complex with beta integrins in vitro. J. Cell Biol. 130, 1181-1187.

Schaller, M.D., and Parsons, J.T. (1995). pp125 $5^{\mathrm{FAK}}$-dependent tyrosine phosphorylation of paxillin creates a high-affinity binding site for Crk. Mol. Cell. Biol. 15, 2635-2645.
Schaller, M.D., and Sasaki, T. (1997). Differential signaling by the focal adhesion kinase and cell adhesion kinase beta. J. Biol. Chem. $272,25319-25325$.

Schlaepfer, D.D., Hanks, S.K., Hunter, T., and van der Geer, P. (1994). Integrin-mediated signal transduction linked to ras pathway by GRB2 binding to focal adhesion kinase. Nature 372, 786-791.

Schwartz, M.A. (1993). Spreading of human endothelial cells on fibronectin or vitronectin triggers elevation of intracellular free calcium. J. Cell Biol. 120, 1003-1010.

Schwartz, M.A., Both, G., and Lechene, C. (1989). The effect of cell spreading on cytoplasmic $\mathrm{pH}$ in normal and transformed fibroblasts. Proc. Natl. Acad. Sci. USA 86, 4525-4529.

Schwartz, M.A., Cragoe, E.J., and Lechene, C.P. (1990). Regulation of cytoplasmic pH in spread cells and round cells. J. Biol. Chem. 265, 1327-1332.

Serra-Pages, C., Kedersha, N.L., Fazikas, L., Medley, Q., Debant, A., and Streuli, M. (1995). The LAR transmembrane protein tyrosine phosphatase and a coiled-coil LAR-interacting protein colocalize at focal adhesions. EMBO J. 14, 2827-2838.

Seufferlein, T., and Rozengurt, E. (1994). Lysophosphatidic acid stimulates tyrosine phosphorylation of focal adhesion kinase, paxillin and p130. J. Biol. Chem. 269, 9345-9351.

Shaw, L.M., Rabinovitz, I., Wang, H.H.F., Toker, A., and Mercurio, A.M. (1997). Activation of phosphatidylinositide 3-OH kinase by the alpha 6 beta 4 integrin promotes carcinoma invasion. Cell 91, 949960.

Shen, Y., Schneider, G., Cloutier, J.F., Veillette, A., and Schaller, M.D. (1998). Direct association of protein-tyrosine phosphatase PTPPEST with paxillin. J. Biol. Chem. 273, 6474-6481.

Tahiliani, P.D., Singh, L., Auer, K.L., and LaFlamme, S.E. (1997). The role of conserved amino acid motifs within the integrin beta 3 cytoplasmic domain in triggering focal adhesion kinase phosphorylation. J. Biol. Chem. 272, 7892-7898.

Tamura, M., Gu, J.G., Matsumoto, K., Aota, S., Parsons, R., and Yamada, K.M. (1998). Inhibition of cell migration, spreading, and focal adhesions by tumor suppressor PTEN. Science 280, 1614-1617.

Thomas, J.W., Ellis, B., Boerner, R.J., Knight, W.B., White, G.C., and Schaller, M.D. (1998). SH2- and SH3-mediated interactions between focal adhesion kinase and Src. J. Biol. Chem. 273, 577-583.

Turner, C.E., and Miller, J.T. (1994). Primary sequence of paxillin contains putative $\mathrm{SH} 2$ and $\mathrm{SH} 3$ binding motifs and multiple LIM domains: identification of a vinculin and pp $125^{\mathrm{FAK}}$-binding region. J. Cell Sci. 107, 1583-1591.

Wood, C.K., Turner, C.E., Jackson, P., and Critchley, D.R. (1994). Characterization of the paxillin-binding site and the C-terminal focal adhesion targeting sequence in vinculin. J. Cell Sci. 107, 709717.

Yamada, K.M., Aota, S., Akiyama, S.K., and LaFlamme, S.E. (1992). Mechanisms of fibronectin and integrin functions during cell adhesion and migration. Cold Spring Harb. Symp. Quant. Biol. 57, 203212.

Yu, D.H., Qu, C.K., Henegariu, O., Lu, X., and Feng, G.S. (1998). Protein-tyrosine phosphatase Shp-2 regulates cell spreading, migration and focal adhesion. J. Biol. Chem. 273, 21125-21131.

Zheng, C., Xing, Z., Bian, Z.C., Guo, C., Akbay, A., Warner, L., and Guan, L. (1998). Differential regulation of Pyk2 and focal adhesion kinase (FAK). The C-terminal domain of FAK confers response to cell adhesion. J. Biol. Chem. 273, 2384-2389. 